\title{
A case study of cortical colour "blindness" with relatively intact achromatic discrimination
}

\author{
C A HEYWOOD, B WILSON,* A COWEY \\ From the Departments of Experimental Psychology, University of Oxford and the Rivermead Rehabilitation \\ Centre, Oxford, UK
}

SUMMARY A patient is described whose most striking visual disorder was a grossly impaired ability to discriminate between different colours (hues) that were matched for brightness. In contrast his ability to discriminate between different neutral greys presented in the same fashion was much less abnormal, even though the greys were perceptually difficult. Although visual acuity was reduced and visual fields were constricted, and the patient's memory was moderately impaired, these associated symptoms could not themselves be the cause of his unusual colour vision. The patient had the symptoms of cerebral achromatopsia, and the relative preservation of his form vision (when his reduced acuity is taken into account) and his achromatic vision supports the view that the many different visual cortical areas recently demonstrated in the brains of monkeys, and presumed to exist in man, have a perceptual specialisation that matches their physiological differences.

Cerebral achromatopsia is a severe disturbance of the perception of colour caused by cerebral cortical damage. The patient has great difficulty in discriminating between hues and commonly complains that the world looks drained of colour. Although the term achromatopsia implies that vision has become colourless, colours may still be perceived, albeit faintly (that is, they are desaturated). The condition contrasts sharply with other acquired disorders of colour vision where the primary fault is a disconnexion syndrome or a semantic disorder involving the use of colour words (see reference 1 for review) or an impaired ability to remember perceived colours for more than a few seconds. ${ }^{2}$ There are several reports which suggest that cerebral achromatopsia can appear without accompanying deficits in the perception of depth, form, acuity, movement or any other psychophysical dimension. ${ }^{34}$ However, the disturbances are often accompanied by apperceptive visual agnosia $^{5}$ and the cortical damage invariably involves

Address for reprint requests: Dr CA Heywood, Department of Experimental Psychology, South Parks Road, Oxford OX13UD, UK.

*Present Address: Department of Psychology, Charing Cross Hospital, Fulham Palace Road, London W68RF, UK.

Received 20 December 1985.

Accepted 3 February 1986. the ventromedial occipito-temporal region. Such findings have been used as evidence for the parallel nature of processing in the visual system. ${ }^{67}$ In support of this, the electrophysiological work of Zeki ${ }^{8}$ has revealed a cortical area in the rhesus monkey, area V4, that shows a relative specialisation for the analysis of colour. Recently, Heywood and Cowey (in preparation) have shown that surgical removal of cortical visual area V4 in macaque monkeys leads to disturbances in hue discrimination that resemble cerebral achromatopsia, that is, closely separated but not widely separated hues are poorly discriminated. However, these deficits in monkeys were not accompanied by similar disturbances in the discrimination of neutral grey stimuli but were accompanied by severe deficits in pattern discrimination. In other words the animals behaved like a patient with achromatopsia and an apperceptive pattern disorder.

The present paper reports the examination of a patient suffering bilateral occipital infarction and whose colour vision was grossly impaired. We were especially interested in testing his achromatic vision to determine whether this was intact or much less impaired, as in monkeys after removal of V4.

\section{Case report}

C.B. is a 28 year old, highly educated man who performs documentary research for the Civil Service. In August 1984 he was involved in a road traffic accident resulting in a right 
frontotemporal skull fracture. He was conscious but confused on admission to hospital and there were no severe immediate neurological deficits. However, 18 hours later his conscious level deteriorated and the right pupil became dilated and fixed. He withdrew to pain on the right side but had a left hemiparesis. A right frontal craniotomy was performed and an extradural haematoma removed. Bleeding from the frontal burr-hole continued and the left pupil also became dilated, although it reacted sluggishly to light. At a second operation the same day a small craniectomy was extended to the floor of the temporal fossa, a large extradural clot was removed, and the site of the bleeding from the middle meningeal artery was coagulated. A CT scan 2 weeks later showed residual slight oedema over the right frontotemporal region and a serpiginous abnormality bilaterally in the occipital region. At this point the patient appeared to be blind. Perception of light in either eye returned over the next few days. Both optic discs showed pallor and there was ptosis on the right side. The right pupil was still dilated but now responded sluggishly to light. The response of the left pupil was normal. Right second and third nerve paresis together with cortical blindness were found. His vision improved over the next few weeks until he could read letters in newspaper headlines. A repeat CT scan showed no evidence of the occipital abnormalities, which were therefore thought to have been caused by infarction and arterial compression. He was discharged home 4 weeks after the accident. In January 1985 he was admitted to the Rivermead Rehabilitation Centre for assessment and treatment.

\section{Psychological assessment}

Detailed testing was initially carried out from 6 to 8 months after the accident. Further tests were carried out 7 months later as indicated in the text.

1 General CB could see large objects and readily detected movement, but he could often not identify what he saw. He could read large but not small print. Vision was patchy. He appeared to have a left homonymous hemianopia. Although he had no motor problems he had a marked topographical amnesia and was disoriented even in his own home, but memory for his surroundings was much improved 7 months later. He had a lively interest in current affairs and could remember their details well. But his episodic memory for other recent events, such as whether he had had lunch, was poor. His writing was good.

2 Intellectual CB was tested on the WAIS and demonstrated a verbal IQ of 136 that is remarkably high even in a normal subject. Performance IQ could not be satisfactorily tested because of visual deficits.

3 Reading CB was asked to read single letters of various sizes at a normal reading distance of about 15 inches. All letters of the alphabet were tested. The number correct out

Table Number correct out of 26 for the identification of upper and lower case letters

\begin{tabular}{lllll}
\hline & \multicolumn{5}{l}{ Size of letters } \\
\cline { 2 - 5 } & $7 \mathrm{~mm}$ & $5 \mathrm{~mm}$ & $3.5 \mathrm{~mm}$ & $2 \mathrm{~mm}$ \\
\hline Upper case & 19 & 16 & 14 & 5 \\
Lower case & 16 & 12 & 11 & 3 \\
\hline
\end{tabular}

of 26 is displayed in the table. The clear size effect, where performance deteriorates with a reduction in letter size, suggests a visual sensory disturbance. This interpretation was supported in a task that required CB to match a spoken word to one of six alternative written words which included words that were semantically, phonetically, visually or acoustically similar to the correct one and a random word. CB scored 21/30 correct and six of the nine errors were to the visually similar alternative. When asked to read words printed in $5 \mathrm{~cm}$ letters he got only four out of 16 correct. Errors were clearly attributable to a visual field loss, for example missing-out letters as in "ring" for "bring" and "hen" for "then". Seven months later reading showed substantial improvement for both words and single letters. CB accurately read text made up of $4 \mathrm{~mm}$ lower case letters at the normal reading distance (Reading Test Types, N.24).

4 Naming There was little impairment in CB's ability to name either pictures of objects or real objects, as shown by the following scores:

Real objects (visual)-14/15 (failed empty cotton reel)

Real objects (tactile) $-10 / 10$

Model animals-8/10 (giraffe-horse, goat-foal)

Wingfield-Oldfield Naming Test (pictures)-34/36

In the last of these tests the two errors appeared to be of a visual nature, that is, toothbrush = hairbrush, anchor = pickaxe. In a subsequent task CB was asked to select from four pictures of objects, the object that matched a spoken word. The three incorrect pictures were visually or semantically similar or random, respectively. The score of $36 / 60$ included 19 visual errors but only four semantic errors which is consistent with a disorder that is predominantly sensory as opposed to cognitive. In support of this view, 7 months later (ie. 15 months after the accident) CB was presented with a picture matching task. On each of 24 trials he was presented with three black and white photographs, two of which were different views of the same object, the third being of a different object. The task was to match the identical objects. He scored 20/24 and succeeded in naming the object on every occasion, except when failing to make the correct match.

5 Memory Memory was tested using the Associate Learning of the Wechsler Memory Scale and the Rey Auditory-Verbal Learning Test. In the former, CB scored 10 (Standardisation Group, 15.72, SD 2.81). In the latter, the score of eight was within the normal range for List $I$ but showed no improvement for repeated presentations. An autobiographical memory interview yielded accurate recall with some chronological errors. In a test of Logical Memory (prose recall) CB scored 9/23 and 10/23 on immediate recall, which although within normal limits, is less than would be expected considering his high IQ. On delayed recall the scores of $7 / 23$ and $0 \cdot 5 / 23$ were discrepant. CB thus had some evidence of impaired memory for personal events, spatial surroundings and written material. However, when tested 7 months later on a stylus maze and using the most difficult condition, where the correct path is not demonstrated and the stylus must be returned to the start point after any error, he solved two routes that involved 6 and 10 choice points in only 5 and 16 trials, respectively.

6 Visual fields Dynamic perimetry carried out on 11 occasions between 5 and 6 months after the accident revealed a stable pattern of visual field loss. There was a left 


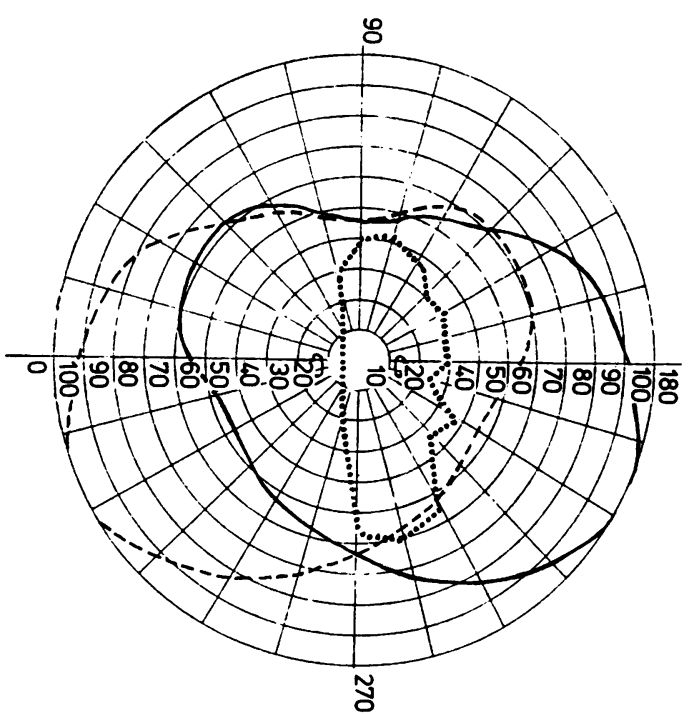

Fig 1 The figure shows a representative result of perimetric testing taken from 12 such tests performed between 5 and 8 months after the accident. The dashed line encloses the residual visual field of $C B$ when tested binocularly. The stimulus was a $1.7^{\circ} 0.34 \mathrm{~cd} \mathrm{m^{-2 }}$ white spot against $a-43.55$ $c d m^{-2}$ background in an Aimark Perimeter.

homonymous hemianopia and a patchy field loss in both upper right quadrants. The field loss appeared substantially greater in the right eye than the left. A representative measure of CB's binocular visual field is presented in fig 1 . 7 Visual acuity Five months after the accident Snellen Acuity in the left eye was $6 / 24$ and could not be improved with lenses. With the right eye only finger counting was possible. Acuity was measured more systematically 10 months after the accident using high contrast sinusoidal gratings created by moire fringes. The circular test field was placed $57 \mathrm{~cm}$ from the subject and subtended $6^{\circ}$ of visual angle. The spatial frequency of the grating was varied systematically using a staircase procedure and CB was required to report the presence or absence of a grating using a method of forced choice. Twenty-five spatial frequencies were used ranging from $1 \mathrm{cycle} / \mathrm{degree}$ to 20 cycles/degree. Acuity was defined as the spatial frequency at which performance was $75 \%$ correct. This was obtained from the curve relating percentage correct to spatial frequency. Once the rough threshold had been determined 11 trials were given at each spatial frequency in the range containing the threshold. Measured in this way CB's binocular grating acuity was 7 cycles/degree, which is close to the Snellen Acuity of 6/24 measured earlier for the left eye, corresponding to an acuity of 7.5 cycles/degree.

8 Visual Shape Perception CB was tested on visual shape perception using a task of Efron. ${ }^{10}$ The task requires the subject to discriminate a square from a rectangle that is matched for total flux. Task difficulty is manipulated by varying the ratio of the height to width of the rectangle. CB was tested first on simultaneous discrimination where both square and rectangle were presented side by side on a video monitor using a computer controlled display. He was then tested with successive presentations of square or rectangle at random. The size of the standard square was $51 \mathrm{~mm} \times 51 \mathrm{~mm}$ and the rectangle was made to successively approximate the square by incrementing the height in $0.5-1 \mathrm{~mm}$ steps while keeping the area constant. During simultaneous discriminations the relative vertical position of the two discriminanda was varied to prevent the discrimination being performed on the basis of displacement of a single horizontal edge. The discriminations were presented as blocks of 10 . If the score for a block was eight or more correct, the discrimination was made more difficult, for a score of six or less, it was made easier, for the subsequent block. For a score of seven the level of difficulty was maintained. CB's threshold performance (defined as the point before which a discrimination is failed on two consecutive occasions) was a $2 \mathrm{~mm}$ and a $6.5 \mathrm{~mm}$ discrepancy between height and width for simultaneous and successive discriminations, respectively. These figures are substantially less than those reported for agnosic patients of Warrington ${ }^{4}$ and Efron ${ }^{10}$ and are totally consistent with impaired acuity and normal shape perception.

9 Face Recognition Disturbances of colour vision following cerebral damage are frequently accompanied by impaired recognition of previously known familiar faces, that is, prosopagnosia. Although CB reported no difficulty in recognising the faces of friends, he was tested on a face recognition task. He had little difficulty in reporting the names of famous people when presented with black and white photographs of faces of politicians, actors and sportsmen. In contrast he scored poorly on Warrington's Recognition Memory Test for unfamiliar faces. A score of 31 (Standardisation Group, 43.6, SD 3.3) is perhaps not surprising in view of CB's poor acuity and patchy delayed recall. There was therefore no evidence that CB was prosopagnosic.

10 Colour Perception CB had no difficulty in naming the colour of common objects from memory but was grossly impaired when asked to name the colours of objects with which he was confronted or which lay in his immediate surroundings. He described his surroundings as being darkly coloured, as in an unlit room at twilight, even when they were bathed in sunlight. Formal tests of colour vision were presented from 7 to 9 months after the accident, as follows: (1) Farnsworth-Munsell 100-Hue Test. The 100-Hue Test actually has only 88 hues in four groups of 22 . A group of 22 is presented in random but predetermined order in a single row. The observer has to sort them so that there is an orderly progression of hues along the row between the predetermined anchor hues at each end. Each coloured chip is $13 \mathrm{~mm}$ in diameter. CB sat at a table in a room in which the sole illumination was provided by two 20 watt fluorescent tubes (Thorn, artificial daylight, colour temperature $6500^{\circ} \mathrm{K}$ ) placed $120 \mathrm{~cm}$ directly above the table. The stimuli were presented on the top of the table and CB was able to pick them up and examine them from whatever distance he preferred. He was tested on the series of hues and, in addition, a series of 22 "greys" that differ in reflectance in an orderly fashion from "dark" to "light". The ordering of chromatic and achromatic stimuli are, for the normal observer, matched for difficulty.

Figures 2 and 3 show his performance for chromatic and 


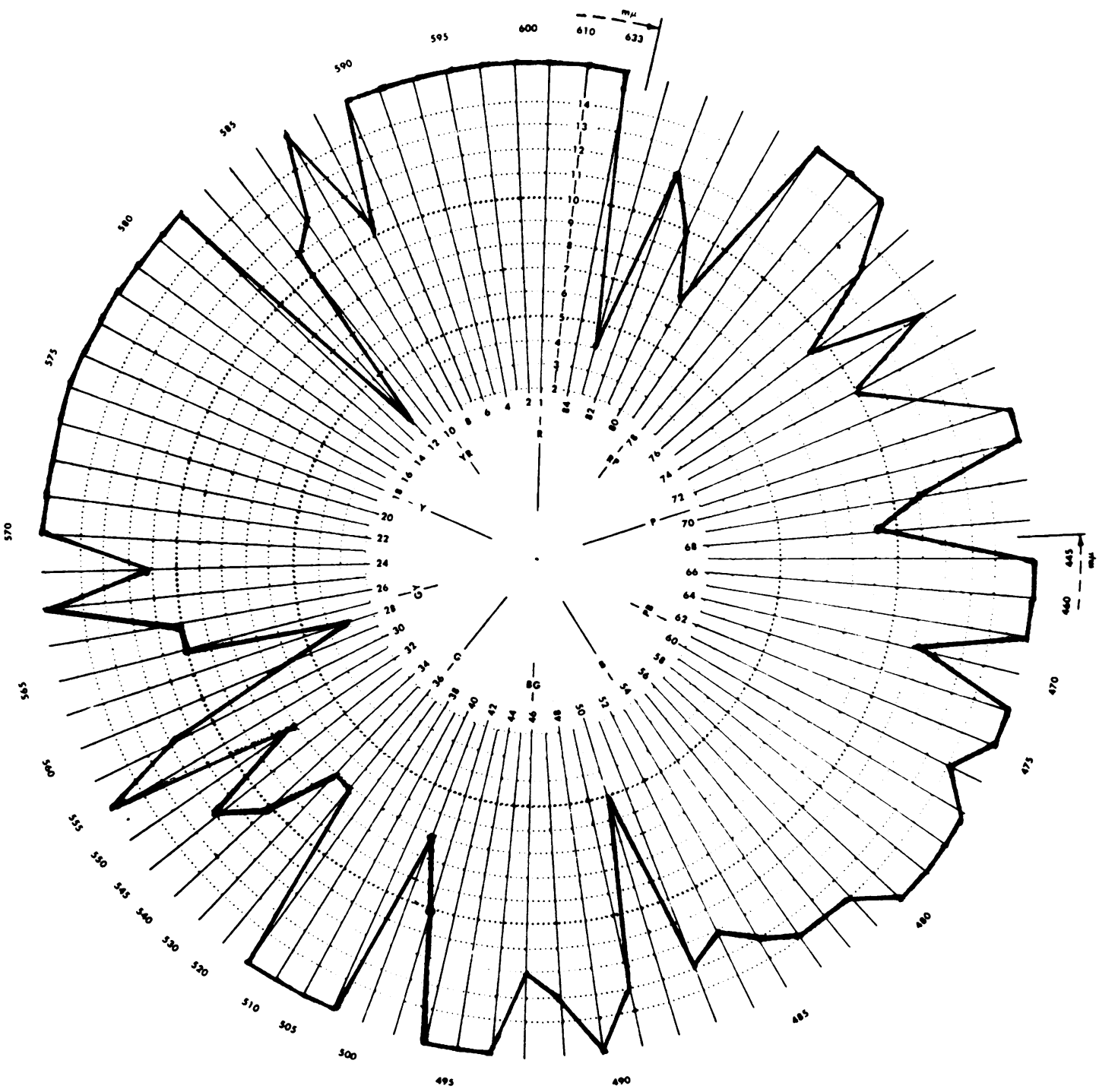

Fig 2 Results of the Farnsworth-Munsell 100-Hue Test. Errors are plotted radially and positions on the circumference represent points along a continuum of hue.

achromatic stimuli, respectively. The results indicate that his colour vision is markedly impaired relative to that of normal observers. There is perhaps a suggestion that he experienced the greatest difficulty in the discrimination of hues falling in the red/yellow-green part of the spectrum (nos. 85-21). However the most conspicuous finding was that his performance on the series of achromatic stimuli was substantially better than that of chromatic stimuli although still showing some impairment relative to normal observers. Since the task of ordering a series of colours by a subject with reduced visual fields and poor acuity may well reflect things other than discriminative ability, particularly when the discriminanda are small, a similar task was performed using a different stimulus set.

(2) Ordering of Munsell Colour "Swatches" The task was essentially the same as the one described above but the stimuli now consisted of coloured Munsell papers, each measuring $75 \mathrm{~mm} \times 50 \mathrm{~mm}$. There were 11 papers in each of 3 widely separated parts of the spectrum, namely, reds $(2 \cdot 5 R / 6 / 12-5 Y R / 6 / 12))$, yellow/greens 


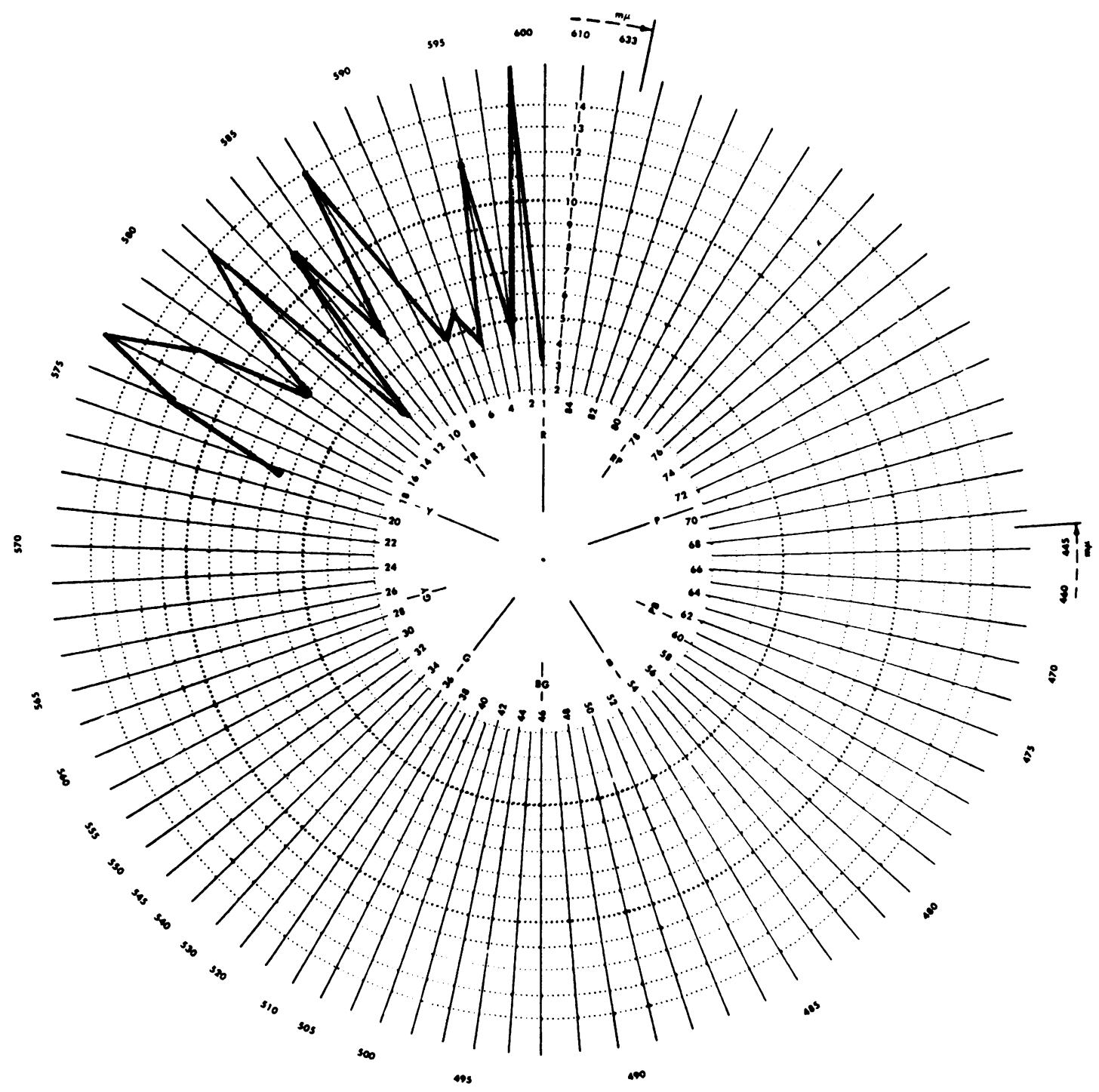

Fig 3 The results of testing the discrimination of a series of achromatic greys in a manner identical to the $100 \mathrm{Hue}$ test. The results are plotted in a similar fashion as fig 2 for the purposes of comparison.

$(2 \cdot 5 G Y / 7 / 12-10 Y R / 7 / 12)$ and blues $(10 G / 6 / 8-5 P B / 6 / 10)$. In addition there were 11 achromatic papers differing, not in hue, but in reflectance $(\mathrm{N} 2 \cdot 5-\mathrm{N} 7 \cdot 5)$ and nine papers differing in neither hue nor subjective brightness, but in saturation (N6.0-2.5YR/6/16). In each case CB was required to put each series into a smooth order of colour, greyness or saturation after the stimuli were presented to him in a random array. The ordering of chromatic and achromatic stimuli was designed to be of approximately equal difficulty by selection of the stimuli on the basis of what is known of the equivalence of the dimensional scales of hue, saturation and reflectance. ${ }^{11} 12$

The results largely confirmed the findings reported above. When asked to name the colour of the different Munsell series CB described the reds and the yellow-greens as "orange" and "pale orange" respectively, the blues as 


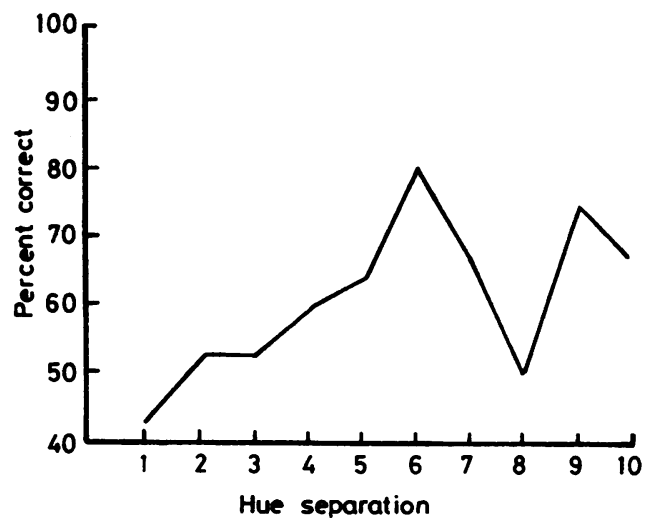

Fig 4 Percentage correct plotted against hue separation in a task where the patient had to pick the odd colour in three coloured plaques. The units of separation are arbitrary, corresponding to 1.25 Munsell steps for the series of reds and green/yellows and 2.5 steps for the series of blues. In this way task difficulty is approximately equal for discrimination of hues in the three portions of the series.

"greenish blue". The saturation series was correctly described as "dull orange" and the greys as "grey". As a measure of his ability rank correlation coefficients were calculated between the observed and expected orders. These were, for two repeated observations, Reds, 0.51; Yellow/Greens, 0.33; Blues, 0.73. For the red and blue ranges, the results indicate that the ordering was statistically different from random at the $5 \%$ level. However, the ordering of the yellow/greens was not significantly different from random $(p<0.2)$. Again, for the series of greys and for the ordering of a series on the basis of saturation, performance was better than with hues. Thus the associated correlation coefficients were now 0.88 and 0.87 respectively. Comparatively better performance on the blues, compared with the other two hues, can be explained by the fact that adjacent hues in the blue range were subjectively twice as far apart on the Munsell scale than adjacent hues in the red or yellow/green ranges. In summary, CB demonstrates a greatly increased threshold for the discrimination of hue, with relatively preserved ability to discriminate on the basis of reflectance. However, the severity of the impairment may be exacerbated by the requirements of a task requiring ordering of a number of stimuli. It was clear that, in the presence of constricted visual fields, CB could only solve the task by successive pairwise comparison of the stimuli, that is he could not see the entire series at once and therefore inspected parts of it in turn. This may occasionally lead to gross transposition of a number of elements of the series as a result of a single, uncharacteristic error. A further test was therefore conducted requiring the solution of an "oddity" problem under conditions where a reduced visual field should have no effect on performance.

(3) Tests of "oddity" performance. The colour stimuli described above were used. However, on each trial CB was presented with only 3 stimuli, two of which were identical, the third differing in the appropriate dimension (hue, reflectance or saturation). The task required the subject to select the odd one out. He reported that he could see all three swatches simultaneously and he was allowed to move them in whatever way he wished. For each series of stimuli, each member was paired twice (in the case of saturation four times) with every other member of the same series in the oddity problem. This yielded 110 trials for each of the three series of hues and the greys and 144 trials in the case of saturation. It was then possible to plot percentage correct against separation, that is, steps apart on the Munsell scale in arbitrary units, to obtain some objective measure of the degree of impairment. Figures 4, 5, 6 show the results for performance on the series of hues, greys and saturations, respectively.

Responding randomly would result in a score of $33 \%$ correct. For each separation the number of trials contributing to the mean is obviously different (for example for each series of eleven hues there are six trials at the maximum separation of 10 , increasing by six trials per step as the separation is reduced, so that there are 60 trials at a separation of one step). The effect of this is to exaggerate the contribution of single errors at wide hue separations to the overall curve. With increasing hue separation CB's performance improved, confirming that there is not a complete absence of colour vision. However as with previous tests it is clear that there is a marked increase in the threshold at which different hues can be reliably discriminated. It must be pointed out however that $C B$ took five to ten times longer than a normal observer to make each judgement. Again, performance on saturation and reflectance discrimination, although impaired relative to a normal observer, was substantially better.

Seven months after these data were collected he was retested on the blue range of swatches and on the achromatic series. The results were unchanged.

(4) Ishihara Pseudoisochromatic Plates. He inspected each of the 38 plates in turn at a distance of about 12 to 14 ins $(30-35 \mathrm{~cm})$ and was asked to identify any apparent number or numbers within the plate and to point to them or follow

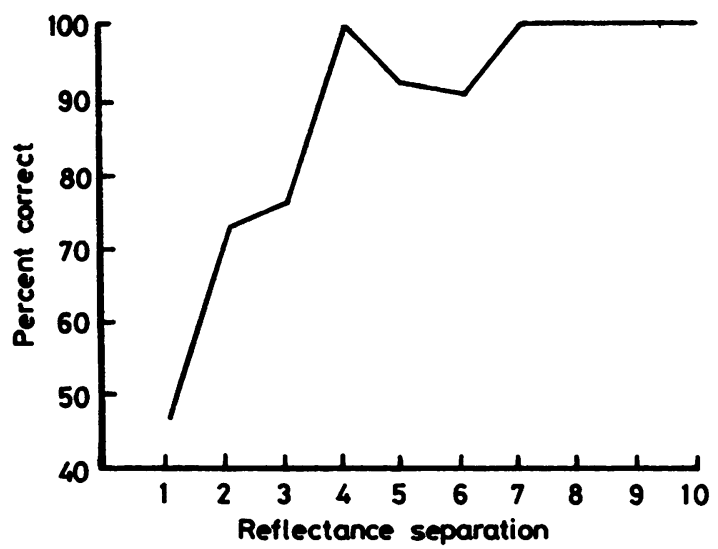

Fig 5 Percentage correct plotted against separation when the patient had to select the odd grey in three grey plaques. As an approximation to equating task difficulty with that for hues, the arbitrary units represent 0.5 Munsell steps. 


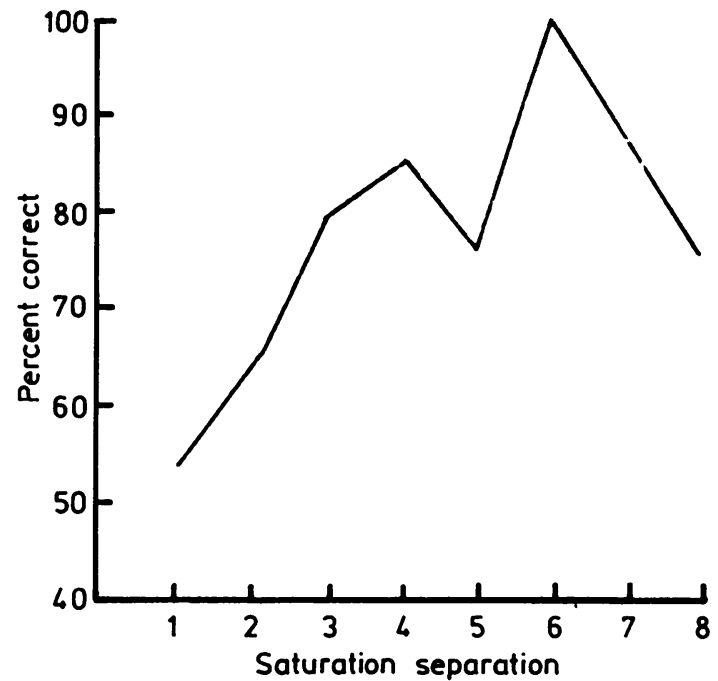

Fig 6 Legend as for fig 5, but for the discrimination of saturation. The arbitrary units now' represent 2 Munsell steps.

their outline with his forefinger. He failed every plate except the first, which does not require colour vision for its detection. The patient described by Mollon et $a l^{12}$ could read the plates correctly at a distance of 2 metres despite failing at normal reading distance. He failed at the longer distances, where he could also no longer read plate 1 , presumably becaused of his defective visual acuity.

\section{Discussion}

A patient such as $\mathrm{CB}$ is of special neurological interest because his perceptual disturbance is of crucial relevance to the question of whether the cortical analysis of colour is at some stage physically dissociated from the analysis and representation of other visual attributes such as shape, disparity, achromatic contrast, and movement. ${ }^{671415}$ Although reports of selective disturbances of colours have appeared sporadically since the end of the nineteenth century, many are undoubtedly examples of colour anomia accompanying a disconnexion syndrome (that is, optic aphasia), or a disturbance in the semantic memory for colour words or in immediate memory for colours or colour words. In other examples the appropriate tests were not carried out to exclude these possibilities. Holmes ${ }^{16}$ and Teuber et $a l^{17}$ concluded that there was no good evidence of an isolated loss of colour vision as a result of cortical damage. However, in reviewing 14 reports of alleged achromatopsia Meadows ${ }^{1}$ made clear that the defect was neither semantic not memonic although it was usually associated with prosopagnosia and topographical amnesia, and invariably with a visual field defect. Case 1 of Damasio et $a l^{3}$ comes closest to displaying hemi- achromatopsia in its purest form, but discrimination thresholds for hues were not measured and no evidence was presented about the discrimination of greys. Patient MS, studied by Newcombe and Ratcliff ${ }^{18}$ and by Mollon et $a l^{13}$ underwent an especially thorough psychophysical examination and although his hue discrimination was essentially random... "he could detect small differences in shades of grey". Unfortunately MS also suffered from visual agnosia, including prosopagnosia, and taken in isolation does not demonstrate that cortical processing of colour is separably vulnerable to cortical damage. The perceptual status of CB is particularly important when considered in connexion with the reports by Meadows, ${ }^{1}$ Newcombe and Ratcliff, ${ }^{18}$ Damasio et $a l^{3}$ and Mollon et al. ${ }^{13}$ Although the localisation of the cortical lesion is poor in CB and his colour defect is not absolute, his pattern of deficits confirms that achromatopsia need not be accompanied by frank apperceptive object agnosia. Provided visual stimuli were large enough to be resolvable their shape was usually identified correctly. However, it could be argued that orientation was not systematically varied and tested along a continuum like hue and that had this been done impairments greater than those attributable to poor acuity may have been detectable. This should be tested in future, but a patient whose performance on the 100-hue test is essentially random would be expected to show gross errors in shape and orientation discrimination if there is a more generalised defect affecting these attributes to the same extent as hue. We are handicapped of course by having no established norms for the discrimination of orientation and shape in a test analogous to the Farnsworth-Munsell test for hue. Nevertheless, the present results do show that the visual defect is not common to all visual thresholds. CB's performance on neutral greys was substantially better than his performance with hues, despite the fact that the stimuli were presented in identical fashion and the perceptual difficulty of the greys and the hues was similar for normal observers. Moreover, his performance with a constant hue of varying saturation was also better than with different hues of the same saturation. The results with CB therefore confirm and systematically extend the otherwise isolated observation by Newcombe and Ratcliff ${ }^{18}$ that patient MS could detect different shades of grey.

Although it is now clear that cerebral achromatopsia can exist as a relatively isolated apperceptive visual disorder, the nature of the colour disturbance itself is still not established. The common description of a world "drained of colour" suggests that although the visual pathways remain trichromatic ${ }^{13}$ hue is no longer consciously perceived or acknowledged. However, some recent reports of the visual receptive field 
properties of single neurons in the prestriate colour area (V4) in oldworld monkeys indicate that many of the cells here (but not elsewhere) respond selectively to colour as opposed to spectral composition of the stimulus within the receptive field of the cell, that is a cell responds when the stimulus within its receptive field looks a particular colour to a human observer despite wide variations in the wavelengths of the light that is incident on the stimulus and its surroundings. In other words the cell shows colour constancy. It is difficult to see how cerebral achromatopsia could arise solely as a result of impaired colour constancy. For example, colours might be expected to be inconstant but they should neither disappear nor appear identical when viewed alongside each other. The mechanism of colour constancy may well be damaged in cerebral achromatopsia but the greater disorder appears to lie in the cortical registration and discrimination of different hues prior to that.

It is a pleasure to thank Dr E Rushworth for allowing us to see the patient and include the neurological report in our paper, D Westbrook for presenting some of the Neuropsychological Tests, and Dr Freda Newcombe and Dr E De Haan for helpful discussion and the loan of a stylus maze and tests of object and face recognition. The investigation was supported by the Medical Research Council and the Oxford Area Health Authority.

\section{References}

1 Meadows JC. Disturbed perception of colours associated with localized cerebral lesions. Brain 1974;97:615-32.

2 Davidoff JB, Ostergaard AL. Colour anomia resulting from weakened short-term colour memory. Brain 1980;107:415-31.

3 Damasio A, Yamada T, Damasio H, Corbett J, McKee J. Central achromatopsia: Behavioral, anatomic, and physiologic aspects. Neurology 1980;30:1064-71.

4 Warrington EK. Visual deficits associated with occipital lobe lesions in man. In: Chagas C, Gattass R, Gross C (eds) Pattern Recognition Mechanisms. Pontificiae
Academiae Scientiarum Scripta Varia 1985;54:247-61.

5 Critchley M. Acquired anomalies of colour perception of central origin. Brain 1965;88:711-24.

6 Cowey A. Cortical maps and visual perception. The Grindley Memorial Lecture. $Q J$ Exp Psychol 1979; 31:1-17.

7 Cowey A. Sensory and non-sensory visual disorders in man and monkey. Phil Trans $R$ Soc Lond. series B, 1982;298:3-13.

8 Zeki SM. Uniformity and diversity of structure and function in rhesus monkey prestriate visual cortex. J Physiol (Lond) 1978;277:273-90.

9 Zeki SM. Colour coding in the cerebral cortex: The reaction of cells in monkey visual cortex to wavelengths and colours. Neuroscience 1983;9:741-65.

10 Efron R. What is Perception? Boston Studies in the Philosophy of Science. New York: Humanities Press Inc, 1968:137-73.

11 Nickerson D. The specification of color tolerances. Textile Res 1936;6:505.

12 Bellamy BR, Newhall SM. Attributive limens in selected regions of the Munsell Color solid. J Opt Soc Am 1942;32:465-73.

13 Mollon JD, Newcombe F, Polden PG, Ratcliff G. On the presence of three cone mechanisms in a case of total achromatopsia. In: Verriest G ed. Colour Vision Deficiencies. Bristol; V Hilger, 1980:130-5.

14 Cowey $A$. Why are there so many visual areas? In: Schmitt FO, Worden FG, Adelman G, Dennis SG eds. The Organization of the Cerebral Cortex. Cambridge, Mass. MIT Press, 1981:395-413.

15 Cowey A. Aspects of cortical organization related to selective attention and selective impairments of visual perception. In: Posner MI, Marin OSM eds. Attention and Performance $X I$. New Jersey: Lawrence Erlbaum Associates, 1985:41-62.

16 Hoimes G. Disturbances of vision by cerebral lesions. Br J Ophthalmol 1918;2:353-84.

17 Teuber HL, Battersby WS, Bender MB. Visual Field Defects after Penetrating Missile Wounds of the Brain. Cambridge, Mass Harvard University Press, 1960.

18 Newcombe F, Ratcliff G. Agnosia: A disorder of object recognition. In: Michel F, Schott B eds. Les Syndromes de Disconnexion Calleuse chez l'Homme. (Colloque International de Lyon 1974) Lyon, Hôpital Neurologique de Lyon 1975:317-41. 